\title{
9 \\ ACESSO A DOCUMENTOS DE ACORDOS DE LENIÊNCIA ANTITRUSTE PARA FINS DE PRIVATE ENFORCEMENT NO BRASIL E NA UNIÃO EUROPEIA
}

\section{Access to Leniency related documents to promote private enforcement in Brazil and in the european union}

Allan Fuezi Barbosa

João Otávio Bacchi Gutinieki²

\section{RESUMO}

O presente artigo discute o acesso a documentos derivados de acordos de leniência antitruste, para fins de propositura de ações de reparação de danos, a partir de uma comparação entre o regime jurídico de acesso a documentos brasileiro e da União Europeia. Para tanto, realiza-se o estudo das Ações de Reparação por Danos Concorrenciais no Brasil e do programa de leniência do Conselho Administrativo de Defesa Econômica, como também do regime jurídico aplicável aos documentos entregues à autoridade antitruste pelo beneficiário da leniência. Ademais, examina-se as ações de reparações de danos e do regulamento dos acordos de leniência no direito da União Europeia. Conclui-se que a dificuldade na comprovação a existência do cartel implica a maior recorrência de ações follow-on, de modo que a inversão do ônus da prova de danos deve ser aplicada, para além da necessidade de acesso a determinados documentos apresentados por signatários das leniências nas persecuções públicas.

Palavras-chave: Reparação de danos. Acordos de Leniência. Acesso a documentos. Direito Antitruste. Ônus da prova.

\section{ABSTRACT}

The paper aims to discuss access to documents derived from leniency agreements for the purpose of supporting private enforcement actions, relying on a comparison between the Brazilian and the

1 Mestre no perfil Direito e Economia pela Faculdade de Direito da Universidade de Lisboa, com período na Alma Mater Studiorum - Università di Bologna. Investigador Associado ao Centro de Investigação de Direito Europeu, Económico, Financeiro e Fiscal - CIDEEF. Participante do Comitê de Concorrência do IBRAC. Administrador. E-mail: allanfuezibarbosa@gmail.com,

2 Mestrando em Direito Econômico e Financeiro na Faculdade de Direito da Universidade de São Paulo (FD-USP). Monitor do curso de especialização em Direito Econômico do FGVLAW - Escola de Direito de São Paulo da Fundação Getúlio Vargas (FGV DIREITO SP). Advogado. E-mail: joaogutinieki@hotmail.com 
European Union legal regimes. Therefore, we analyze private enforcement actions in Brazil and the leniency program of the Brazilian antitrust authority, as well as the legal regime applicable to documents delivered to the antitrust authority by the leniency recipient. Moreover, we examine the damages actions and the regulation of leniency agreements in European Union law. We conclude that difficulty in proving the existence of cartel implies a greater attendance of follow-on actions, so that the reversion burden of proof is suitable as well as the access to leniency related documents in public enforcement.

Keywords: Private enforcement. Leniency agreements. Access to documents. Antitrust Law. Burden of proof.

Sumário: 1. Introdução. 2. O private enforcement no Brasil. 2.1. O programa de leniência brasileiro. 2.2. A confidencialidade (ou a publicidade) dos processos com leniência. 2.3. A Resolução no 21/2018 e o acesso à documentação. 3. O private enforcement na União Europeia. 3.1. A leniência na União Europeia. 3.2. $O$ acesso à documentação da Comissão em casos de leniência. 4. Considerações finais. Referências.

\section{INTRODUÇÃO}

A ação de reparação privada de danos na seara concorrencial (private enforcement) teve como um dos seus pilares históricos a legislação norte-americana do Clayton Act, de 1914, especificamente em sua Section 4, na qual há previsão do o chamado treble-damage ${ }^{3}$, que corresponde ao dever de indenizar em até o triplo do dano causado em decorrência de práticas anticoncorrenciais, de modo que as ações privadas dispõem de finalidade não apenas compensatória, mas punitiva. Essa previsão normativa secular e os altos retornos financeiros das ações acabaram por gerar uma tradição nos Estados Unidos do private enforcement em matéria concorrencial, que representam mais de noventa por cento dos processos, muitos dos quais com o objetivo de ressarcimento de danos particulares em práticas anticoncorrenciais (BERRISH; JORDAN; ROLDAN, 2004, p. 591-592).

Contudo, as realidades brasileira e da União Europeia são bastante diversas quanto a essa disciplina norte-americana, mormente diante do fato de não haver essa tradição nos referidos sistemas em análise. Em regra, as ações de reparação privada de danos concorrenciais (private enforcement) acabam por ser um sucedâneo (ação follow-on) dos processos públicos para a imposição de sanção por infração à ordem econômica (public enforcement), sobretudo em relação às práticas cartelistas, as quais são de difícil comprovação e condenação, e que se valem, na maioria das vezes, de mecanismos de consensualidade, como os acordos de leniência, para o alcance da finalidade do microssistema concorrencial. the United States in the district in which the defendant resides or is found or has an agent, without respect to the amount in controversy, and shall recover threefold the damages by him sustained, and the cost of suit, including a reasonable attorney's fee.[...]". Em livre tradução, "Exceto conforme disposto na subseção (b) desta seção, qualquer pessoa que sofra danos em seus negócios ou propriedade, em razão de qualquer proibição prevista nas leis antitruste, pode processar o responsável em qualquer tribunal distrital dos Estados Unidos, no distrito em que o réu resida ou seja encontrado ou tenha mandatário, independentemente do valor em controvérsia, devendo o responsável ressarcir o triplo dos danos por ele sofridos e as custas do processo, incluindo honorários advocatícios razoáveis. [...]". 
Assim sendo, nos contextos em análise no presente artigo, para as condutas anticoncorrenciais de maior complexidade - como as cartelizações -, os agentes econômicos privados que foram lesados pela prática anticoncorrencial, em razão da sua baixa capacidade para a obtenção de provas relevantes da prática, acabam por se valer de um conjunto probatório do public enforcement, mormente daquelas persecuções públicas que têm no seu bojo a celebração de acordos de leniência. Esses, por sua vez, detêm mecanismos de proteção dos signatários, não somente pela concessão de benefícios, mas de sigilo de documentos e informações apresentadas.

Diante desse cenário, o presente artigo objetiva analisar de que modo, para a propositura de ação reparatória privada de danos concorrenciais nos sistemas brasileiro e da União Europeia, pode o agente lesado se valer do acesso de documentos de acordos de leniência em public enforcement, com vistas à comprovação dos requisitos necessários à verificação do dever de indenizar dos violadores da norma concorrencial em questão.

\section{O PRIVATE ENFORCEMENT NO BRASIL}

No Brasil, a aplicação efetiva do Direito Antitruste tem um desenvolvimento recente, uma vez que o regime anterior à Constituição Federal de 1988 tinha uma prevalência de preços regulados, em uma economia planificada (BERCOVICI, 2006, p. 237-238), o que, por vezes, institucionalizava o falseamento do mercado (TAVARES, 2015, p. 1053-1055). Logo, apenas em 1994, com a edição da Lei no 8.884, que estruturou o Sistema Brasileiro de Defesa da Concorrência, passou-se a ter public enforcement mais contundente no país (BRASIL, 1994).

Em matéria do private enforcement, a Lei de Defesa da Concorrência (LDC) - a Lei n. 12.529/2011 - prevê o direito de ação em seu artigo 47 (BRASIL, 2011). Ou seja, há a previsão legal, para a propositura de ação judicial pelo lesado, independentemente de inquérito ou processo administrativo no Conselho Administrativo de Defesa Econômica (Cade), para a busca de reparação pelos danos sofridos por infrações à ordem econômica previstas no artigo 36, caput, da mencionada Lei.

Sob essa perspectiva, a Resolução do Cade n. 21/2018 (BRASIL, 2018), especialmente em seu artigo 12, concedeu um incentivo a uma cultura de reparação extrajudicial de danos, como vantagem aos representados que sofrerão penalidades, quando da comprovada reparação de danos, por via judicial ou extrajudicial, como circunstância atenuante no cálculo da contribuição pecuniária devida no Termo de Compromisso de Cessação (TCC) ou nas multas aplicadas conforme os artigos 37 e 38 da LDC.

Todavia, a despeito da possibilidade de propositura das ações de reparação de danos decorrentes de práticas anticoncorrenciais e até a sua reparação extrajudicial, o processo de obtenção de provas em condutas de alta complexidade - como o cartel (FORGIONI, 2015, p. 151) - gera um desincentivo à reparação privada, sob qualquer circunstância. Isso, porque a comprovação dos elementos configuradores da responsabilidade de reparar é bastante complicada, até mesmo para o public enforcement, o que não seria diferente para a hipótese das persecuções privadas. Afinal, os agentes econômicos se valem de meios para inviabilizar o acesso às provas das suas práticas, como a não formalização dos atos, a utilização de comunicação indireta, bem como o manejo de tecnologias de difícil interceptação etc. 
Nesse contexto, a leniência pode ter um papel fundamental não apenas na persecução pública perante as autoridades de concorrência, mas como um importante meio de obtenção de provas para a utilização em ações de private enforcement, pelo que se torna necessário um breve panorama dessa figura no ordenamento jurídico brasileiro. Afinal, representa um meio de concessão de benefícios diretos, nos âmbitos administrativo e criminal, como também indiretos, em decorrência do receio de que outra pessoa fisica ou jurídica, anteriormente, firme um acordo dessa natureza (LESLIE, 2004, p. 641). Resta, portanto, saber como se estrutura esse instituto concorrencial no sistema jurídico brasileiro.

\subsection{O programa de leniência brasileiro}

O Programa de Leniência Antitruste do Conselho Administrativo de Defesa Econômica tem origem em 2000, a partir da edição da Medida Provisória n. 2055-4, de 7 de dezembro, como uma importante ferramenta para o public enforcement do direito da concorrência, sob a justificativa da dificuldade de obtenção de provas da prática de determinados ilícitos concorrenciais, notadamente quando da possibilidade de paralelismo comportamental (FORGIONI, 2015, p. 151). Por conseguinte, o mencionado diploma fora convertido na Lei no 10.149, de 21 de dezembro de 2000, que incluiu na então legislação antitruste, a Lei no 8.884, de 11 de junho de 1994, nos artigos 35-B e 35-C, a possibilidade de estabelecimento de acordo de leniência.

A leniência é, pois, um mecanismo de consensualidade administrativa representada pela transação entre a estrutura estatal e o beneficiário, por meio da "troca de informações viabilizadoras da instauração, da celeridade e da melhor fundamentação do processo, [que] possibilita um abrandamento ou extinção da sanção em que este incorreria [...]", em razão da prática da conduta anticoncorrencial (OLIVEIRA; RODAS, 2013, p. 244-245). Em outras palavras, concede-se beneficios às pessoas jurídicas e físicas participantes de uma conduta anticoncorrencial, a partir do compromisso de confissão e de cessação da prática ilícita, para além da necessária cooperação com as investigações, mediante a indicação dos participantes e a apresentação de informações e documentos fundamentais para a apuração dos fatos.

Esse conjunto de iniciativas permanece na atual Lei n. 12.529/2011, em seus artigos 86 e 87, como forma de detecção, investigação e punição das infrações contra a ordem econômica, como também de informação e orientação as empresas e os cidadãos, de modo permanente, acerca dos direitos e garantias do acordo de leniência, como forma de incentivar, orientar e assistir a celebração da leniência concorrencial (BRASIL, 2016, p. 9).

Ao longo dessa evolução normativa, algumas modificações foram implementadas, como a competência para a celebração do acordo, que passou da Secretaria de Direito Econômico do Ministério da Fazenda para a Superintendência-Geral do Cade, a partir da nova lei. Essa modificação tem um impacto positivo, na medida a competência destinada a um órgão da própria estrutura do Cade (sem ingerência política) permite a redução dos custos de transação e da possibilidade de atuações desconexas, como ocorria na vigência da lei anterior.

Conquanto outros acordos de leniência possam ser firmados perante outras instituições como o Ministério Público (MP) ou a Controladoria-Geral da União (CGU), esses não excluem a competência 
da Superintendência-Geral do Cade (SGC) para a celebração do acordo na seara antitruste (BRASIL, 2016, p. 11). Essa atribuição da Superintendência-Geral do Cade, entretanto, não garante a concessão dos benefícios definitivamente, uma vez que esses apenas são conferidos quando do julgamento do processo administrativo pelo Plenário do Tribunal do Cade (art. 86, §4으, da Lei no 12.529/2011).

Como outros avanços legislativos da nova LDC, permitiu-se que o líder do cartel firmasse o acordo (CORDOVIL et al, 2011, p. 191), ao tempo que houve a abrangência normativa explícita dos efeitos do instituto no âmbito penal (art. 87, da Lei no 12.529/2011), bem como criou-se a regra de impedimento de nova leniência no prazo de três anos, como um desincentivo ao descumprimento do acordo (§ 12으, do artigo 86, da LDC), conforme sustentado por Oliveira e Rodas (2013, p. 247) e Marrara (2015, p. 335).

Particularmente em relação à leniência corrente, existem três modalidades de o proponente solicitar o acordo de leniência junto à Superintendência-Geral do CADE (MARRARA, 2015, p. 335): na fase pré-processual (de modo antecedente à investigação pela autarquia), superveniente e relacionado a um único processo (acerca de fatos apurados em um procedimento já instaurado), bem como em um processo já existente, com extensão a outro fato a ser investigado pela autarquia, fato que acarretaria na instauração de novo processo administrativo.

No tocante às sanções administrativas, a previsão normativa do caput do artigo 86 , da Lei n. 12.529/2011, prevê a extinção da ação punitiva para o primeiro beneficiário da leniência, se a Superintendência-Geral do Cade não tiver conhecimento prévio da infração noticiada, ou a redução de 1 a 2/3 da penalidade aplicável, para os beneficiários subsequentes, ou em caso de conhecimento prévio da $\mathrm{SGC}^{4}$. Então, o interessado qualificado para a celebração do acordo recebe do Superintendente-Geral o marker, documento que comprova o seu status e, logo, as garantias decorrentes da sua qualificação (BRASIL, 2016, p. 25). Isso, porque a qualificação do primeiro a celebrar o acordo referido pode conferir ao signatário a cessação total das penas de natureza administrativa.

Quanto à seara penal, observa-se que a celebração da leniência enseja a suspensão do prazo prescricional e a impossibilidade de oferecimento da denúncia em relação aos beneficiários, motivo pelo qual exige-se a intervenção do Ministério Público Federal na celebração do instrumento, pelo fato de ser esse o titular da ação penal por condutas anticoncorrenciais (CORDOVIL et al, 2011, p. 192). Por sua vez, nos termos do artigo 87, da LDC, cumprido o acordo de leniência, há ainda a extinção da pretensão punitiva penal dos crimes tipificados na Lei de Crimes Contra a Ordem Econômica (Lei no 8.137/1990), bem como em outras legislações correlatas, como os carteis tipificados na Lei Geral de Licitações (Lei no 8.666/1993), ou o crime de associação criminosa, disposto no artigo 288 do Código Penal.

Demais disso, há uma garantia geral do sigilo ao programa de leniência. Desse modo, o § 9 o do artigo 86, da LDC, impede a publicidade da proposta de acordo de leniência oferecida à Superintendência-Geral, como forma de tornar atrativo o instituto àqueles que participaram de uma infração concorrencial e desejam colaborar com a autoridade concorrencial.

4 A seu turno, como consequência da extinção ou da redução referidas sanções administrativas, as penalidades acessórias dispostas no artigo 38, da LDC, igualmente devem ser afastadas em relação aos signatários da leniência que cumprem regularmente o quanto disposto nos termos do acordo. 
Por outro lado, as condutas infracionais em questão, em regra, geram danos diretos ao mercado, o que dá aos prejudicados o direito de postular reparações pelos prejuízos sofridos, através de ação judicial, comumente denominada por Ação de Reparação por Danos Concorrenciais (ARDC), ou private enforcement concorrencial. Nesse aspecto, o microssistema concorrencial, apesar de não poder desguarnecer os beneficiários da leniência, como o sigilo supramencionado, tampouco pode tornar impossivel a reparação aos lesados pelas práticas anticoncorrenciais. Por conta disso, entendese fundamental saber como se desenha o arcabouço normativo acerca do acesso à documentação e informações constantes em processos administrativos e inquéritos perante o Cade, por pessoas que tenham interesse em pleitear a reparação dos danos sofridos em decorrência do ilícito concorrencial.

\subsection{A confidencialidade (ou a publicidade) dos processos com leniência}

De um modo geral, para a persecução eficiente dos seus fins, a Lei de Defesa da Concorrência dispõe, em seu artigo 49, do tratamento sigiloso, pelo Tribunal e pela Superintendência-Geral do Cade, de documentos, informações e atos processuais que sejam necessários à elucidação dos fatos, ou mesmo ao cumprimento do interesse da sociedade, seja no inquérito administrativo para a apuração de infrações à ordem econômica (inc. II, art. 48, LDC) ou no seu correlato processo administrativo para a imposição de sanções administrativas por tais ilícitos (inc. III, art. 48, LDC). Ademais, o parágrafo único do referido artigo 49 ainda menciona a possibilidade de requerimento, pelas partes, de tratamento sigiloso de documentos e informações, nos limites definidos no Regimento Interno do Cade (RICade) (BRASIL, 2019).

Especificamente no que tange aos acordos de leniência, o §9o do artigo 86, da LDC garante o sigilo à proposta de acordo de leniência, ressalvado o interesse das investigações e do processo administrativo. Isso porque, não pode a autoridade, no caso da leniência, permitir que outros envolvidos no ilícito descubram que estão sendo delatados, até a abertura do processo administrativo, uma vez que isso poderia causar ocultação de provas e claros prejuízos à investigação (PEREIRA NETO; CASAGRANDE, 2015, p. 186-187).

Desse modo, será dado acesso aos representados do acordo de leniência, dos seus anexos e dos respectivos documentos, apenas para fins de exercício de defesa no inquérito ou processo administrativo (inc. I, §2o- do artigo 207, do RICade), sendo vedada a divulgação ou o compartilhamento desses elementos de prova (inc. I, §2º, do artigo 207, do RICade) (BRASIL, 2019). A publicização da identidade do signatário do acordo de leniência, por sua vez, de acordo com o artigo 207 do RICade, apenas se dará com o julgamento do processo pelo Tribunal do Cade, mantendo-se, entretanto, o acesso restrito quanto aos documentos e às informações que sejam comercialmente sensíveis (\$1ํ, do art. 207, do RICade).

Portanto, em regra, de acordo com a normatização concorrencial, terceiros não teriam acesso direto às provas e informações apresentadas pela parte que firmou um acordo de leniência, devendo ser respeitadas as condições e prazos de confidencialidade estabelecidos pelo regramento antitruste.

Diante desse cenário, resta saber de que modo os lesados por infrações concorrenciais podem aceder à documentação relativa a um inquérito ou a um processo administrativo em que se tenha firmado um acordo de leniência com um dos infratores. É o que será analisado no item 
subsequente, como forma de garantir o follow-on das ações public enforcement pelas demandas de private enforcement.

\subsection{A Resolução $n^{\circ} 21 / 2018$ e o acesso à documentação}

Em um contexto marcado por entendimentos diversos em relação ao acesso a documentos do acordo de leniência para fins de propositura de ação de reparação de danos concorrenciais, o Cade editou a Resolução n²1, de 11 de setembro de 2018. Como mandamento geral, reconheceu-se a publicidade dos documentos e informações constantes nos processos administrativos para a imposição de sanções por infrações à ordem econômica, incluindo-se aqueles oriundos de acordo de leniência (art. 10-, da Resolução n. 21/2018), tendo a sua divulgação dependente da fase processual (BRASIL, 2018).

Contudo, o artigo 2o, da mencionada resolução, impôs exceções à regra geral de publicidade, para a manutenção da restrição de acesso mesmo depois da decisão final do Plenário do Tribunal do Cade, ou seja, com a impossibilidade de disponibilização a terceiros 5 . Primeiramente, entende-se como confidencial o histórico da conduta e seus aditivos elaborados pela Superintendência-Geral do Cade, que tenham como fundamento documentos e informações de natureza auto acusatória, submetidos pelos proponentes, voluntariamente, no âmbito da consensualidade administrativa. Isso, por conta do risco à condução das negociações, às atividades relativas à inteligência e à própria efetividade do programa de leniência, ou de eventual termo de cessação de conduta (inc. I, art. 2o- da Resolução n. 21/2018).

Para além do histórico de conduta e seus aditivos, no caso da leniência, que é o foco do presente trabalho, também figuram sob confidencialidade, de acordo com o inc. Il do referido art. 2ㅇ, da Resolução n. 21/2018, os documentos e as informações: a) relativos à proposta de acordo de leniência e demais necessários à elucidação dos fatos, ou exigidos pelo interesse da sociedade; b) que representem segredo industrial; c) em relação à atividade empresarial da pessoa cuja divulgação possa representar vantagem competitiva para outros agentes econômicos; d) relativos ao sigilo fiscal, bancário, de operações e serviços no mercado de capitais, além de comercial, profissional, industrial, de justiça, entre outras hipóteses previstas expressamente em legislação; e) cujo sigilo fora imposto em procedimento administrativo junto ao Cade, nas hipóteses previstas em seu Regimento Interno; f) cujo sigilo fiscal fora determinado por decisão judicial; g) relacionados à proposta de negociação do acordo de leniência frustrado, enquanto não foram restituídos aos proponentes, ou inutilizados pelo Cade.

0 acesso aos documentos e informações indicados como de restritos pelo artigo 2 o da mencionada resolução apenas será concedido em quatro hipóteses (art. 3o, da Resolução n. 21/2018): a) determinação legal expressa; b) decisão judicial específica quanto ao acesso; c) autorização do beneficiário da leniência, com a anuência do Cade, desde que sem prejuízo à investigação; d) em razão de cooperação jurídica internacional, consoante previsão dos artigos 26 e 27 do Código de Processo

5 A mencionada resolução, diferentemente do art. 48 do RICade, não diferencia sigilo de acesso restrito. Para o presente trabalho, adota-se a expressão de "confidencialidade" para qualquer das figuras com impedimento de acesso público, quais sejam: sigilo, acesso restrito e segredo judicial. 
Civil (CPC), mediante autorização do Cade e autorização do beneficiário da leniência, desde que não haja prejuízo à investigação.

Nesse passo, a questão da confidencialidade é tão relevante que pode ensejar responsabilização administrativa, civil e penal daquele que utiliza ou divulga a terceiros documentos e/ou informações sigilosas (art. 40-, da Resolução n. 21/2018). Por conta disso, os signatários da leniência devem informar a existência medidas judiciais e extrajudiciais em andamento no Brasil e no exterior sobre documentos e informações presentes do acorno (art. 5ㅇ, da Resolução n. 21/2018), e a Procuradoria Federal junto ao Cade poderá intervir em feitos relacionados ao tema e requerer suspensão de processos, para evitar o comprometimento da política nacional de combate às infrações à ordem econômica (art. 6o- da Resolução n. 21/2018). Ainda em seguimento à política da confidencialidade, segundo o art. 70., da Resolução n. 21/2018, o Ministério Público que atuar como interveniente na celebração do acordo de leniência, apesar de ter acesso integral aos documentos e às informações apresentadas pelo proponente, deverá observar as regras de confidencialidade, para a propositura de procedimentos cíveis e criminais cabíveis ao caso.

Ademais, a referida resolução especifica o grau de publicidade documental para cada fase do processo administrativo sancionador que tenha como base o acordo de leniência, ou outros meios consensuais não tratados no presente artigo. Na fase de negociação e de celebração dos acordos, a previsão é da manutenção do sigilo da proposta e dos documentos consectários do acordo de leniência, somente podendo pessoas autorizadas pelo Cade acessá-los por um dos seguintes fundamentos: a) necessidade de preservação da investigação e da identidade do colaborador (inc. l, art. 9o- da Resolução n. 21/2018); b) a necessidade de preservação da política nacional de combate às infrações contra a ordem econômica (inc. II, art. 9o-, da Resolução n. 21/2018); c) a necessidade de preservação da participação do Brasil em programas internacionais de combate às infrações contra a ordem econômica (inc. III, art. 9o-, da Resolução n. 21/2018).

Por sua vez, na fase de instrução do processo administrativo para imposição de sanções administrativas por infrações à ordem econômica, realizado perante a SGC ou no Tribunal do Cade, há a previsão da disponibilização nos autos de versões públicas da nota técnica de instauração e da nota técnica final da SGC (art. 10, da Resolução n. 21/2018). As notas técnicas, em que pese não fornecerem todas as informações sobre o caso, já oferecem substantivo fundamento aos interessados em ingressar com a ARDC, fundamentadas no artigo 47, da Lei de Defesa da Concorrência (BRASIL, 2011).

Enfim, quando da decisão final pelo plenário do Tribunal do Cade, deve-se conceder o acesso ao conteúdo de acesso restrito que assim eram classificados apenas para a preservação da instrução (art. 11, da Resolução n. 21/2018). Afinal, a garantia do acesso a documentos e informações que eram sensiveis no momento da investigação e da instrução, torna-se importante para medidas de private enforcement. Todavia, os documentos tidos como sigilosos ou em segredo de justiça não podem ser disponibilizados, de modo generalizado, conforme os incisos III e IV, do art. 48, do RICade, de modo que somente poderiam ocorrer em casos excepcionais, mediante autorização criteriosa da autarquia ou do Poder Judiciário, respectivamente.

O dies ad quem da confidencialidade documental da leniência fora tratado no julgamento do caso do "Cartel dos Compressores", perante o Superior Tribunal de Justiça (STJ), o qual reconhecera "necessidade de um maior elastecimento do sigilo, a fim de abarcar o julgamento pelo órgão admi- 
nistrativo" (STJ, 2018), com vistas ao efetivo funcionamento do instituto da leniência, em detrimento da consideração anterior de que o termo seria da "apresentação do relatório circunstanciado pela Superintendência-Geral ao Presidente do Tribunal Administrativo" (STJ, 2016). Em todo caso, ressaltou-se, em que pese o programa de leniência da autoridade antitruste brasileira trazer premiações na esfera administrativa e penal, o instituto “[...] não alcança a responsabilidade civil decorrente do dever geral de não lesar outrem, de forma que poderá vir a ser responsabilizado pelos prejuízos que sua conduta causou a particulares" (STJ, 2018). E, assim sendo, a jurisprudência reafirma o quanto disposto na Resolução n. 21/2018, para a acessibilidade de documentação relativa ao acordo de leniência, com vistas à propositura de ação reparatória, após o julgamento pelo Tribunal Administrativo do Cade.

Por outro lado, a despeito do art. 11 da Resolução em questão dispor sobre a publicidade dos documentos, no Despacho Decisório no 44/2019/GAB4/Cade, de 13/11/2019 (BRASIL, 2019), no Processo no 08700.004073/2016-6, de relatoria da Conselheira Paula Farani de Azevedo Silveira ${ }^{6}$, entendeu-se pela irretroatividade da disponibilização dos documentos necessários à propositura de ações cíveis de reparação de danos concorrenciais, para processos em que houve a celebração de acordos pelo Cade, antes da entrada em vigor da mencionada resolução7. Contudo, o precedente do STJ - anterior à vigência da resolução - pode servir como fundamento para o acesso a esse conjunto documental, uma vez que a autoridade administrativa entende pela não liberação de seu acesso, sem um fundamento que seja mais relevante que a reparabilidade dos danos relativos à prática anticoncorrencial.

\section{O PRIVATE ENFORCEMENT NA UNIÃO EUROPEIA}

No contexto da União Europeia (UE), apenas nas últimas décadas que se passou a ter em conta a utilização dos meios de persecução privada para a reparação dos danos advindos de práticas anticoncorrenciais (WILS, 2003, p. 473-476). São relativamente recentes as decisões do Tribunal de Justiça da União Europeia (TJUE) que reconheceram o direito à reparação privada de danos concorrências, como no caso Courage v Crehan (LUXEMBURGO, 2001) e, em especial, no caso Manfredi, a partir do qual se estabeleceu, com fundamento no antigo art. 810 (atual 101으), do Tratado sobre o Funcionamento da União Europeia (TFUE), que "[...] qualquer pessoa pode invocar a nulidade de um acordo ou de uma prática proibida por este artigo e, quando existe um nexo de causalidade entre esta e o dano sofrido, pedir a reparação do referido dano" (LUXEMBURGO, 2006, p. I-6659).

Como na realidade brasileira, o private enforcement na União Europeia é incipiente e pautado em sistema predominantemente de Civil Law, de modo que o mecanismo de responsabilização

6 Despacho referendado pelo plenário do Cade, em 149a Sessão Ordinária de Julgamento, realizada em 13 de novembro de 2019. No mesmo sentido, ver Despacho no 49, de 23 de dezembro de 2019, no Processo no 08700.007938/2016-41, Rel. Cons. Paula Farani de Azevedo Silveira, em 22/01/2020.

7 In verbis: “Nesse sentido, muito embora a referida Resolução tenha como principal objetivo fomentar as ações civis de reparação por danos concorrenciais, é preciso, por outro lado, respeitar os termos dos acordos celebrados anteriormente à sua entrada em vigor, em atenção ao art. 5o, inciso XXXVI, da Constituição Federal, e art. 6o da Lei de Introdução às normas do Direito Brasileiro. 5. Mantenho, portanto, a confidencialidade dos documentos e informações que integram o apartado de acesso restrito no 08700.004108/2016-61". 
privada de danos concorrenciais tem no acesso a elementos de prova um dos fatores decisivos para o sucesso do instrumento. Isso decorre muito das culturas jurídicas desses locais, que ensejam maior preocupação nas soluções normativas, uma vez que as autoridades tendem a interpretar e a aplicar de modo mais cauteloso o dispositivo de viabilização da obtenção dos elementos de prova (ROSSI; FERRO, 2015, p. 133).

Por conta da dificuldade na colheita de provas fundamentais para a comprovação dos elementos da responsabilidade por danos concorrenciais, garante-se aos lesados algum acesso aos meios de prova produzidos em procedimento das autoridades concorrenciais, com maior poder de investigação e coleta de provas. Em razão disso, no âmbito da União Europeia, o private enforcement tem estreito relacionamento com o arcabouço normativo acerca da obtenção das provas pelos que sofreram danos da prática anticompetitiva, sobretudo em casos complexos de condutas anticoncorrenciais, as quais ensejam, muitas vezes, a celebração de acordo de clemência ${ }^{8}$.

Desde já, ressalte-se que o presente artigo se cinge à hipótese de acesso à documentação relativa ao processo atrelado à clemência firmado junto à instituição responsável pela investigação, apuração, instrução e decisão administrativa no âmbito da União Europeia, que é a Comissão Europeia. Isso porque, a partir do advento do Regulamento n. 1/2003 (UNIÃO EUROPEIA, 2002), houve uma multiplicação de regimes de clemência entre os Estados-membros, por meio da descentralização da aplicabilidade do direito comunitário da concorrência. E, por sua vez, não se objetiva especificar uma realidade local, tampouco abordar todo o contexto dos Estados que são membros da União Europeia, visto que o presente trabalho tem objetivo de comparação das regras gerais entre as realidades brasileira e da UE.

Logo, não serão tratados os casos de acesso à documentação em processos na seara dos Estados-membros, tampouco em sede do Tribunal de Justiça da União Europeia. No primeiro caso, em face da grande variabilidade de normatização local (de cada Estado-membro) quanto à disciplina da clemência e do acesso aos elementos de prova, fato que enseja o estudo de uma norma de harmonização pela União Europeia'. Já a hipótese relativa ao TJUE é bastante limitadora, uma vez que, de modo geral, não é possível o acesso por terceiros de peças processuais e documentos adunados pelas partes em ações de competência do TJUE, para além dos acórdãos, relatórios de audiências, opiniões e despachos dos advogados-gerais ${ }^{10}$.

Nesse passo, cumpre-se analisar o programa de leniência da UE, como forma de se observar o regramento do instituto, que serve de base para a produção de provas substanciais à verificação de condutas anticoncorrenciais de natureza grave.

\subsection{A leniência na União Europeia}

8

Denominação utilizada em língua portuguesa, no âmbito da União Europeia, para o que no Brasil se chama “leniên-

cia".

9 Vide a Proposta de Diretiva do Parlamento Europeu e do Conselho COM(2017) 142 final 2017/0063 (COMISSÃO EUROPEIA, 2017).

10 No caso República da Suécia, o TJUE $(2010, \S 99)$ decidiu: “nem o Estatuto do Tribunal de Justiça nem os referidos regulamentos de processo preveem o direito de acesso, por parte de terceiros, aos articulados apresentados ao Tribunal de Justiça no âmbito de processos judiciais" (LUXEMBURGO, 2010). Contudo, o TJUE pode determinar o acesso de documentos em processos da Comissão Europeia, bem como as partes podem divulgar os seus articulados processuais. 
O programa de clemência (ou leniência) da União Europeia teve surgimento em 1996, a partir da "Comunicação da Comissão sobre a não aplicação ou a redução de coimas"1 nos processos relativos a acordos, decisões e práticas concertadas" (JOEU, 1996), sendo o primeiro estatuto da UE para as empresas interessadas em colaborar com as investigações da Comissão, de modo a firma o acordo com essa entidade.

Todavia, em razão de alguns problemas interpretativos e da larga margem de discricionariedade da Comissão no processo decisório, editou-se, em 2002, a "Comunicação da Comissão relativa à imunidade em matéria de coimas e à redução do seu montante nos processos relativos a cartéis" (JOUE, 2002), para assegurar a imunidade ao primeiro requerente do acordo de clemência, como também a aceitação de pedidos de leniência dos líderes do cartel, desde que não tenham exercido coação sobre os demais membros, para além da possibilidade de prestação de declarações orais.

Posteriormente, em 2006, aprovou-se a "Comunicação da Comissão Relativa à imunidade em matéria de coimas e à redução do seu montante nos processos relativos a cartéis" (JOEU, 2006), a partir da qual se instituiu o marcador temporal (\$15, da Comunicação de 2006) para o pedido de imunidade para a primeira empresa, bem como para os patamares de redução das multas dos signatários seguintes, a depender da ordem de pedido de leniência apresentado pelas empresas e desde que satisfeitos os demais requisitos normativos. Esse fomento à corrida entre os infratores para delatar o cartel, contudo, não pode beneficiar de imunidade aquela empresa que tenha praticado coação sobre as outras, mas é possivel a redução das multas aplicáveis a essa (§§12 e 13, da Comunicação de 2006). Do mesmo modo, não pode ser concedida imunidade, na hipótese de a Comissão possuir, na data do pedido de leniência, elementos de prova suficientes para a comprovação da existência da infração concorrencial (\$10, da Comunicação de 2006).

A evolução normativa, até mesmo com a edição da comunicação supramencionada, entretanto, deixou de esclarecer a questão do acesso ao conjunto probatório de processos relacionados a pedidos de leniência, por terceiros interessados na propositura de uma ação privada de reparação de danos concorrenciais. Nesse sentido, há de se analisar a seguir os aspectos atinentes à confidencialidade ou publicidade dos elementos de prova, na hipótese mencionada.

\subsection{O acesso à documentação da Comissão em casos de leniência}

A Comissão Europeia - entidade responsável pela verificação da hipótese de cometimento de infração concorrencial do cartel - tem a legitimidade para o recolhimento de informações concorrenciais sensiveis, sobretudo quanto às estratégias comerciais das empresas implicadas em um processo de investigação das condutas enquadráveis no $n^{\circ}$ 1, do art. 101ㅡ, do TFUE. Nesse sentido, podem ser obtidas informações atinentes aos valores de venda, às cotas de mercado, entre outras (UNIÃO EUROPEIA, 2014, § 79).

Por outro lado, conforme o Regulamento n 1049/2001 (UNIÃO EUROPEIA, 2001), do Parlamento Europeu e do Conselho, relativo ao acesso do público aos documentos do Parlamento Europeu, do Conselho e da Comissão, há um direito amplo de acesso aos documentos das instituições em causa. 
Entretanto, quando os documentos objeto do pleito de acesso estão abrangidos por um domínio específico do direito da União Europeia, como o concorrencial, a interpretação das exceções constantes no art. 40 dessa normativa deve ocorrer tendo em conta o regramento desse ramo específico que, no caso da matéria antitruste, tem sede no Regulamento $n^{\circ} 1 / 2003$, de 16 de Dezembro de 2002, da Comissão Europeia, relativo à execução das regras de concorrência estabelecidas nos artigos 101으 e 102음 do TFUE, bem como no Regulamento n 773/2004 da Comissão, de 7 de Abril de 2004 (UNIÃO EUROPEIA, 2004), relativo à instrução de processos pela Comissão para efeitos dos artigos $81^{\circ}$ e $82^{\circ}$ do Tratado CE.

Assim sendo, o Regulamento n. $1 / 2003$, em seus artigos $27^{\circ}$, $n^{\circ} 2$, e $28^{\circ}$, enquanto o Regulamento n. $773 / 2004$, em seus artigos $6^{\circ}, 8^{\circ}, 15^{\circ}$ e $16^{\circ}$, como também o Regulamento $n^{\circ}$ 1049/2001, no artigo $4^{\circ}, n^{\circ} 3$, segundo parágrafo, determinam a limitação ao acesso ao processo às partes interessadas e aos queixosos (UNIÃO EUROPEIA, 2014, §§ 86 a 88). Não se trata, pois, de uma dissonância desse conjunto normativo concorrencial com a regra de amplo acesso, uma vez que a seara concorrencial busca garantir a promoção das boas práticas administrativas, já que se deve facilitar ao máximo o exercício do direito de acesso aos documentos, em detrimento dos direitos de defesa das partes e do interesse da sociedade ${ }^{12}$.

Em que pese as restrições mencionadas acima, para uma ação de reparação de danos concorrenciais, entende-se não ser necessário o acesso a todos o conjunto documental do processo em causa, de modo que qualquer pessoa que pretenda obter a reparação de um prejuízo em razão de uma conduta verificável no $n^{\circ}$ 1, do art. 101으, do TFUE, deve demonstrar a necessidade dessa obtenção, para que a Comissão Europeia pondere os interesses de acesso ou de sua proteção, levando-se em consideração todos os elementos atinentes ao processo. Quando não houver tal necessidade, a reparação do prejuízo sofrido em função da conduta em questão não constitui um interesse público superior que excepciona a regra de recusa de acesso aos documentos, de acordo com o Regulamento n 1049/2001 (UNIÃO EUROPEIA, 2001).

Por sua vez, com o advento da Diretiva 2014/104/EU, do Parlamento Europeu e do Conselho, de 26 de novembro de 2014, passou-se a consolidar o entendimento jurisprudencialmente firmado no caso do acesso à documentação para a propositura de ação de indenização com fundamento em infrações concorrenciais. Desse modo, partindo-se do caso de estabelecimento de acordos de clemência - enquanto uma cooperação de um cartelista às investigações promovidas por autoridade da concorrência, tendo como contrapartida a dispensa ou a redução de coima (artigo 2o. $n^{\circ} 15$, da Diretiva) - a mencionada normatização estabelece parâmetros de acesso à documentação, que no presente caso terá como foco apenas a relativa aos processos de competência da Comissão Europeia (JOEU, 2014).

12 Ver acórdão da Comissão Europeia contra EnBW Energie Baden-Württemberg AG, § 90, in verbis: “Nestas condições, um acesso generalizado, com base no Regulamento n. ${ }^{\circ}$ 1049/2001, aos documentos que figuram no processo de aplicação do artigo $81 .^{\circ} \mathrm{CE}$ é suscetível de prejudicar o equilíbrio que o legislador da União quis assegurar, nos Regulamentos n.os $1 / 2003$ e 773/2004, entre a obrigação que as empresas em questão têm de comunicar à Comissão as informações comerciais eventualmente sensiveis com o fim de lhe permitir comprovar a existência de um cartel e apreciar a sua compatibilidade como referido artigo, por um lado, e a garantia de proteção reforçada que corresponde, a título de sigilo profissional e de segredo comercial, às informações transmitidas à Comissão, por outro (v., por analogia, acórdãos, já referidos, Comissão/ Éditions Odile Jacob, n. ${ }^{\circ} 121$, e Comissão/Agrofert Holding, n. ${ }^{\circ}$ 62)" (LUXEMBURGO, 2014). 
Assim, consolidou-se a necessidade de concessão de acesso à documentação de processos relativos às infrações concorrenciais, desde que atendidos o princípio da proporcionalidade (artigo 5o, $n^{\circ} 3$ e artigo 6o, $n^{\circ}$ 4, da Diretiva), o sigilo profissional (artigo 5o, $n^{\circ} 6$, da Diretiva) e a garantia prévia do contraditório (artigo 5ㅇ, $n^{\circ}$ 7, da Diretiva). Esse procedimento, pois, deve ter como baliza o princípio da efetividade, para que não haja impedimento ou excessiva dificuldade no exercício do direito à reparação dos danos sofridos pelos lesados, em face da infração concorrencial (artigo 4으, da Diretiva).

De toda maneira, instituiu-se a presunção ilidivel de que o cartel enseja danos (artigo 170, $\mathrm{n}^{\circ}$ 2, da Diretiva), como forma de facilitação e incentivo à propositura de ações de reparação de dano integral (artigo 3o, da Diretiva), em mecanismo de follow-on, uma vez que o nexo de causalidade entre a conduta anticoncorrencial e os danos dos lesados tem embasamento na própria legislação, ainda que seja possivel o seu afastamento.

Nesse diapasão, a Comunicação da Comissão de 2006, mencionada no tópico anterior, fora modificada pela "Comunicação da Comissão Europeia - Alterações à Comunicação da Comissão relativa à imunidade em matéria de coimas e à redução do seu montante nos processos relativos a cartéis", a partir da alteração o parágrafo 34. Essa modificação instituiu que, em relação aos processos na Comissão, somente pode ser concedido acesso aos destinatários de uma comunicação de objeções, desde que as informações obtidas por esse meio sejam exclusivamente utilizadas para fins de processos judiciais ou administrativos, com o intuito de aplicação das regras de concorrência da União, podendo aquele que se utilizar indevidamente dessas informações ser punido pelas regras do mencionado instrumento normativo.

Consoante o atual panorama normativo, em regra, qualquer um com personalidade jurídica com residência ou sede na União pode acessar todos os documentos dos processos administrativos da Comissão Europeia, ainda que os inquéritos possam ser protegidos enquanto estão em tramitação, por presunção juris tantum de que a divulgação é um perigo aos objetivos do próprio procedimento administrativo (ROSSI; FERRO, 2015, p. 139). Entretanto, nas hipóteses de um pedido de leniência, de redução de multa, ou de uma proposta de transação, a informação deve ser inacessível a terceiros, por razões de superior interesse público (UNIÃO EUROPEIA, 2006, §33).

Em outros termos, no âmbito da pretensão de propositura de ação de indenização, tem-se como regra que, respeitando-se o teste de proporcionalidade e os requisitos normativos, o acesso a todos os elementos em posse das autoridades da concorrência por ocorrer a qualquer momento, se qualquer das partes ou terceiros não puderem fornecer tais documentos de modo razoável, desde que os elementos de prova obtidos apenas sejam utilizados em ações reparatórias movidos pela pessoa a quem fora concedido o acesso. Contudo, instituiu-se categorias que Rossi e Ferro (2015, p. 183) denominam de "cinzentas" e "negras", as quais impõem condições ao acesso, ou mesmo o proíbem, parcial ou integralmente.

Os elementos "cinzentos" são aqueles que somente acessáveis para o private enforcement após a conclusão administrativa do processo na Comissão, a saber: a) documento elaborado especificamente para o processo de uma autoridade concorrencial; $b$ ) documento elaborado por uma autoridade da concorrência e encaminhado às partes no âmbito do seu processo; c) propostas revogadas 
de transação ${ }^{13}$. Já os denominados de elementos "negros" correspondem àqueles que não podem ser utilizados em ações de private enforcement, em qualquer momento, somente viabilizando-se acesso ao tribunal, para o controle da decisão administrativa, mormente na hipótese das declarações de clemência e das propostas de transação não revogadas (ROSSI; FERRO, 2015, p. 184).

Se a Comissão Europeia, por outro lado, se mostrar reticente na liberação do acesso a terceiros de documentos importantes para o ingresso de uma ação judicial de private enforcement, por força do $n^{\circ} 3$, do artigo 40 do Tratado da União Europeia (TUE) e do $n^{\circ} 1$, do artigo 15 o do Regulamento (CE) no $1 / 2003$, pode-se se valer de pedido de solicitação pelo tribunal nacional competente para processar a ação de reparação de danos concorrenciais baseada no direito comunitário da concorrência ${ }^{14}$. Esse cenário, contudo, ainda é parte de um processo de conscientização de toda a estrutura institucional da União Europeia acerca da necessidade de promoção do private enforcement no âmbito comunitário e em cada Estado-membro. Até porque, por vezes, a institucionalidade da UE sofre críticas por uma atuação contraditória nessa temática ${ }^{15}$.

De toda sorte, mediante o requerimento do interessado, desde que atendidos o princípio da proporcionalidade, o sigilo profissional e a garantia prévia do contraditório, o tribunal nacional que processa a ação de private enforcement pode determinar a apresentação dos os elementos de prova, pela empresa causadora do dano ou pela autoridade pública que detiver os elementos de provas requeridas pelo interessado, como no referido caso Alstom (ROSSI; FERRO, 2015, p. 182).

\section{CONSIDERAÇÕES FINAIS}

No Brasil e na União Europeia, o desenvolvimento das ações de private enforcement na seara concorrencial, com vistas à reparabilidade dos danos causados por uma infração anticompetitiva, encontra um impedimento claro a sua difusão, que é a coleta de elementos de prova, pelos lesados, para adimplemento dos requisitos necessários ao reconhecimento do dever de indenizar, sobretudo em casos de condutas complexas como o cartel.

Dessa maneira, o terceiro que tenha interesse na persecução privada concorrencial pode se valer de documentos constantes em um procedimento ou em um inquérito em trâmite na autoridade da concorrência em questão, para a obtenção de elementos capazes de provar a conduta lesiva, uma vez que essas entidades públicas detêm capacidade técnica e poder de investigação que os particulares não possuem. Trata-se da chamada ação privada follow-on da persecução pública.

13 Sobre a necessidade de encerramento do processo na Comissão para o acesso ao inquérito, Rossi e Ferro (2015, p. 140) tecem algumas críticas à posição de necessária espera da conclusão do processo administrativo, pois acreditam na perda de efetividade do private enforcement, levando-se em consideração os prazos prescricionais dos Estados-membros e a longa duração dos processos perante os tribunais europeus.

14 Acerca do pedido de tribunal nacional de acesso à documentação de processo de competência da Comissão Europeia, ver o caso Alstom contra a Comissão Europeia, processo T - 164/12, sobretudo o resumo constante no Despacho do Tribunal Geral da Primeira Secção (LUXEMBURGO, 2014).

15 Para Rossi e Ferro (2015, p. 186-187) criticam a atuação ambivalente da Comissão Europeia, por promover o private enforcement ao mesmo tempo em que restringe, de modo significativo, o acesso aos seus próprios processos, comprovando-se a partir do fracasso dessa modalidade de ação, no caso dos elevadores, em ação follow-on proposta perante os tribunais belgas. 
Uma das atribuições exclusivas das autoridades concorrenciais - seja do Cade brasileiro ou da Comissão Europeia - corresponde à possibilidade de celebração de acordo de leniência com os infratores, em troca de benefícios aos signatários, como forma de obtenção de provas em procedimentos administrativos para averiguação de algumas condutas complexas e que podem ser confundidas com paralelismos comportamentais. Entretanto, o acordo de leniência implica a garantia da confidencialidade de alguns documentos e informações, seja para o incentivo ao instituto, como também às investigações e ao interesse público.

Destarte, na hipótese de uma persecução privada enquanto ação follow-on de public enforcement que teve no seu bojo a celebração de um acordo de leniência, o particular lesado poderá ter acesso a alguns documentos e informações, como garantia ao direito de reparação dos seus danos, mas com a limitação que permita a consecução dos objetivos concorrenciais e de seus institutos, como a leniência.

No âmbito brasileiro, pode-se conceder acesso aos documentos restritos da leniência, com o objetivo de propositura de ação reparatória, tão-somente após o julgamento pelo Tribunal Administrativo do Cade. Adverte-se, todavia, que nos casos de sigilo legal ou de segredo de justiça, a regra será pela não possibilidade de acesso desses documentos, nem mesmo após o julgamento referido, ainda que excepcionalissimamente o Cade possa conceder algum acesso aos documentos, mas em casos muito peculiares.

Por sua vez, a realidade da UE dispõe de elementos de prova "cinzentos" - os quais podem ser viabilizados apenas após a decisão administrativa do processo na Comissão -, como também os "negros", que terceiros interessados na propositura de ação de reparação não podem ter acesso, nem depois do encerramento da fase administrativa, a exemplo das declarações de clemência e das propostas de transação não revogadas.

Em todo caso, a despeito da semelhança entres os ordenamentos em análise, a sistemática da União Europeia tem um mecanismo de grande relevância para a hipótese de conduta que mais suscita a autoridade da concorrência firmar acordos de leniência, qual seja, o cartel. Segundo a normatização da UE, há uma presunção juris tantum de que todo cartel gera danos; nesse sentido, inverte-se, em desfavor do cartelista, o ônus da comprovação de que não ocorrera um dano em decorrência daquela prática específica.

Portanto, a presunção de danos do cartel representa um incentivo à promoção do private enforcement, no caso das ações follow-on, na medida em que o lesado não necessitará provar o liame entre a conduta (verificada pela autoridade da concorrência) e o dano. Assim sendo, essa solução da União Europeia pode ser implementada no ordenamento jurídico brasileiro, como uma forma de ampliação dos incentivos à persecução privada concorrencial.

\section{REFERÊNCIAS}

CORDOVIL, Leonor et al. Nova lei de defesa da concorrência comentada: Lei 12.529, de 30 de novembro de 2011. São Paulo: RT, 2001.

BERCOVICI, Gilberto. Constituição econômica e constituição dirigente. In: BONAVIDES, Paulo; LIMA, Francisco Gérson Marques de; BEDÊ, Fayga Silveira (coord.). Constituição e democracia: estudos em 
homenagem ao professor J. J. Gomes Canotilho. São Paulo: Malheiros, 2006.

BERRISCH, Georg; JORDAN, Eve; ROLDAN, Rocio Salvador. E.U. Competition and private actions for damages, the symposium on european competition law. Northwestern Journal of International Law \& Business, v. 24, n. 3, p. 585-600, 2004.

BRASIL. Lei no 8.884, de 11 de junho de 1994. Transforma o Conselho Administrativo de Defesa Econômica (Cade) em Autarquia, dispõe sobre a prevenção e a repressão às infrações contra a ordem econômica e dá outras providências. Brasília: Presidência da República, 1994.

BRASIL. Conselho Administrativo de Defesa Econômica. Despacho Decisório no 44/2019/GAB4/Cade, no Processo no 08700.004073/2016-6, de relatoria da Conselheira Paula Farani de Azevedo Silveira, em 13/11/2019, referendado em 149a Sessão Ordinária de Julgamento, realizada em 13 de novembro de 2019, DOU № 223, terça-feira, 19 de novembro de 2019.

BRASIL. Conselho Administrativo de Defesa Econômica (Cade). Guia Programa de Leniência Antitruste do Cade. Brasília: Cade, 2016.

BRASIL. Conselho Administrativo de Defesa Econômica. Regimento Interno do Cade. Brasília: Cade, 2019. Disponivel em: https:// bit.ly/3uYxMJt. Acesso em: 16 de mar. 2021.

BRASIL. Conselho Administrativo de Defesa Econômica. Resolução no 21, de 11 de setembro de 2018. Disciplina os procedimentos previstos nos arts. 47, 49, 85 e 86 da Lei no 12.529, de 2011, relativos à articulação entre persecução pública e privada às infrações contra a ordem econômica no Brasil. Brasília, Cade, 2018. Disponível em: https:// bit.ly/3u1AbBA. Acesso em: 30 dez. 2020.

BRASIL. Superior Tribunal de Justiça. Acórdão. Embargos de Declaração no Recurso Especial no 1.554.986/SP. 3a Turma. Relator: Min. Marco Aurélio Bellizze. Julgado em 20/02/2018. Disponível em: http:// www.stj.jus.br. Acesso em: 30 maio 2020.

BRASIL. Superior Tribunal de Justiça. Acórdão. Recurso Especial no 1.554.986/SP. 3a Turma. Relator Min. Marco Aurélio Bellizze. Julgado em 08/03/2016. Disponivel em: http://www.stj.jus.br. Acesso em 30 maio 2020.

COMISSÃO EUROPEIA. Proposta de Diretiva do Parlamento Europeu e do Conselho, Bruxelas, 22.3.2017 COM(2017) 142 final 2017/0063 (COD). Disponivel em: https:// bit.ly/3eXnyDB. Acesso em: 29 maio 2020.

FORGIONI, Paula A. Os fundamentos do antitruste. 8. ed. São Paulo: Revista dos Tribunais, 2015.

JORNAL OFICIAL DA UNIÃO EUROPEIA (JOEU). Comunicação da Comissão sobre a não aplicação ou a redução de coimas nos processos relativos a acordos, decisões e práticas concertadas, JOUE C 207, 18.07.1996 p. 4-6. Disponivel em: https:/ / bit.ly/3eYnHqk. Acesso em: 29 maio 2020.

JORNAL OFICIAL DA UNIÃO EUROPEIA (JOEU). Comunicação da Comissão relativa à imunidade em matéria de coimas e à redução do seu montante nos processos relativos a cartéis, JOUE C 45, 19.02.2002, p. 3-5. Disponivel em: http://eur-lex.europa.eu/legalcontent/PT/TXT/PDF/?uri=CELEX:52002XC0219(02)\&from=EM. Acesso em: 29 maio 2020.

JORNAL OFICIAL DA UNIÃO EUROPEIA (JOEU). Comunicação da Comissão Europeia: Alterações à Comunicação da Comissão relativa à imunidade em matéria de coimas e à redução do seu montante nos processos relativos a cartéis. JOUE C 256/1, Portugal, 05/08/2015. Disponivel em: https:// bit.ly/3bBi- 
PoM. Acesso em: 29 maio 2020.

JORNAL OFICIAL DA UNIÃO EUROPEIA (JOEU). Comunicação da Comissão Relativa à imunidade em matéria de coimas e à redução do seu montante nos processos relativos a cartéis, JOUE C 298, 8.12.2006, p. 17. Disponivel em: http://eur-lex.europa.eu/legalcontent/PT/TXT/HTML/?uri=CELEX:52006XC1208(04)\&from=EN. Acesso em: 29 maio 2020.

JORNAL OFICIAL DA UNIÃO EUROPEIA (JOEU). Diretiva 2014/104/UE do Parlamento Europeu e do Conselho, de 26 de novembro de 2014, JOUE L 349/1, 5/12/2014. Disponivel em: https:// bit.ly/3ywfAsO. Acesso em 29 de maio de 2020.

LESLIE, Christopher R. Trust, distrust, and antitrust. Texas Law Review, Austin, v. 82, n. 3, p. 515-680, 2004.

LUXEMBURGO. Tribunal de Justiça da União Europeia. Processos apensos C-295/04 a C-298/04, Manfredi e outros. Acórdão do Tribunal de Justiça (Terceira Secção), de 13 de julho de 2006. Disponível em: https:// bit.ly/3eXMtH5. Acesso em: 31 maio 2020.

LUXEMBURGO. Tribunal de Justiça da União Europeia. Processos apensos C-514/07 P, C-528/07 P e C-532/07 P, República da Suécia e outros. Acórdão do Tribunal de Justiça (Grande Secção), de 21 de setembro de 2010. Disponivel em: https:// bit.ly/3eXnW51. Acesso em: 31 maio 2020.

LUXEMBURGO. Tribunal de Justiça da União Europeia. Processo C-453/99, Courage Ltd contra Bernard Crehan. Acórdão do Tribunal de Justiça, de 20 de setembro de 2001. Disponivel em: https://bit.ly/ 33S8Ebp. Acesso em: 31 maio 2020.

LUXEMBURGO. Tribunal de Justiça da União Europeia. Processo C-365/12 P, Comissão Europeia contra EnBW Energie Baden-Württemberg AG e outros. Acórdão do Tribunal de Justiça (Terceira Secção), 27 de fevereiro de 2014. Disponível em: https:/ / bit.ly/2T0oMFv. Acesso em: 16 março 2021.

LUXEMBURGO. Tribunal de Justiça da União Europeia. Processo T - 164/12. Despacho do Tribunal Geral (Primeira Secção), de 4 de dezembro de 2014. Disponivel em: https://bit.ly/3tWnwA4. Acesso em: 29 maio 2020.

MARRARA, Thiago. Sistema brasileiro de defesa da concorrência: organização, processos e acordos administrativos. São Paulo: Atlas, 2015.

OLIVEIRA, Gesner; RODAS, João Grandino. Direito e economia da concorrência. São Paulo: RT, 2013.

PEREIRA NETO, Caio Mário da Silva. CASAGRANDE, Paulo Leonardo. Direito Concorrencial: doutrina, jurisprudência e legislação. São Paulo: Saraiva, 2016.

ROSSI, Leonor; FERRO, Miguel Sousa. O "private enforcement" do direito da concorrência e o acesso a elementos de prova. Revista de Concorrência e Regulação, n. 2, p. 131-193, 2015.

TAVARES, André Ramos. Facções privadas e política econômica não-democrática da ditadura brasileira. Revista Brasileira de Estudos Constitucionais, Belo Horizonte, ano 9, n. 32, p. 1047-1066, maio/ ago. 2015.

UNIÃO EUROPEIA. Regulamento (CE) n.o 1/2003, de 16 de Dezembro de 2002, da Comissão Europeia, relativo à execução das regras de concorrência estabelecidas nos artigos 101. e 102.o do TFUE, JOUE L 1, de 4.1.2003. Disponivel em: https:// bit.ly/3tYL7Ab. Acesso em: 29 maio 2020. 
UNIÃO EUROPEIA. Regulamento (CE) n. ${ }^{\circ} \mathbf{7 7 3 / 2 0 0 4}$ da Comissão, de 7 de Abril de 2004, relativo à instrução de processos pela Comisão para efeitos dos artigos 81. ${ }^{\circ}$ e 82. ${ }^{\circ}$ do Tratado CE, JOUE L 123 de 27/04/2004. Disponivel em: https:// bit.ly/2S51Owm. Acesso em: 29 maio 2020.

UNIÃO EUROPEIA. Regulamento (CE) n. 1049/2001 do Parlamento Europeu e do Conselho, de 30 de Maio de 2001 relativo ao acesso do público aos documentos do Parlamento Europeu, do Conselho e da Comissão, Jornal Oficial das Comunidades Europeias, 31.5.2001, L 145/43.

WILS, Wouter P. J. Should private antitrust enforcement be encouraged in Europe? World Competition, v. 26, n. 3, p. 473-488, 2003. 